\title{
Injection of botulinum toxin type A (BOTOX) into trigger zone of trigeminal neuralgia as a means to control pain
}

\begin{abstract}
This article illustrates a case of persistent trigeminal neuralgia in a medically compromised 65-year-old female who did not respond to pharmacotherapy. She had undergone several peripheral neurectomies as well as a failed right posterior fossa exploration that resulted in a cerebrospinal fluid leak. Persistent pain over the right external nasal area and right mental region was relieved for several hours after daily injections of bupivacaine. A trial of a single dose of 100 units of botulinum toxin type A (BOTOX) diluted in $2.5 \mathrm{~mL}$ saline was injected into the external nasal trigger zone (60 units) and to the mental nerve region (40 units). She achieved complete pain relief in the external nasal region for 5 months. Pain recurred and the site was again injected with 100 units of botulinum toxin type A (BOTOX). Pain relief at the mental region was partial. This was finally controlled with peripheral neurectomy. The patient was pain free with a maintenance dose of $200 \mathrm{mg}$ carbamazepine daily for about 1 year, after which she elected to undergo stereotactic gamma knife radiosurgery when pain recurred at the external nasal region. (Oral Surg Oral Med Oral Pathol Oral Radiol Endod 2010; 109: e47e50)
\end{abstract}

\begin{tabular}{|l|l|}
\hline Authors: & Ngeow, W. C.; Nair, R. \\
\hline Journal: & $\begin{array}{l}\text { Oral Surgery Oral Medicine Oral Pathology Oral Radiology and } \\
\text { Endodontology }\end{array}$ \\
\hline Year: & Mar 2010 \\
\hline Pages: & E47-E50 \\
\hline DOI: & $10.1016 /$ j.tripleo.2009.03.021 \\
\hline
\end{tabular}

Keywords :

TETANUS TOXIN; RELEASE; SYNAPTOSOMES; TRANSMITTERS; MECHANISMS 
Please cite as :

NGEOW, W. C. \& NAIR, R. 2010. Injection of botulinum toxin type A (BOTOX) into trigger zone of trigeminal neuralgia as a means to control pain. Oral Surgery Oral Medicine Oral Pathology Oral Radiology and Endodontology, 109, E47-E50.

URL :

- http://apps.webofknowledge.com/InboundService.do?SID=U17fAAM11bC7IE321DF \&product $=$ WOS $\& U T=000274956600032 \& S r c A p p=C R \& D e s t F a i l=h t t p \% 3 A \% 2 F \% 2 F$

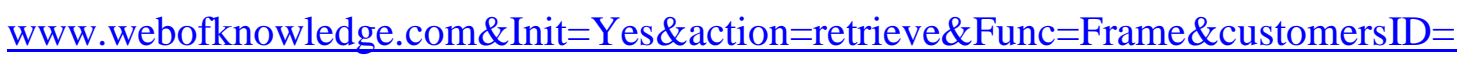
$\underline{\text { RID\&SrcAuth }=\text { RID\&IsProductCode }=\text { Yes \&mode }=\text { FullRecord }}$

- http://www.ncbi.nlm.nih.gov/pubmed/20219585

- http://www.sciencedirect.com/science/article/pii/S107921040900170X

- http://www.mendeley.com/research/injection-of-botulinum-toxin-type-a-botox-into$\underline{\text { trigger-zone-of-trigeminal-neuralgia-as-a-means-to-control-pain/ }}$ 